\title{
Caracterização da linguagem de crianças com desordem do espectro da neuropatia auditiva
}

As possíveis estruturas acometidas na desordem do espectro da neuropatia auditiva (DENA) são as células ciliadas internas, o nervo auditivo e/ou falha na conexão sináptica entre células ciliadas internas e o VIII par craniano. A dificuldade de percepção auditiva da fala no silêncio e, principalmente, no ruído, observada em indivíduos com a desordem, pode ser justificada pela dessincronia neural que leva a uma falha no padrão dos estímulos sonoros enviados para o sistema auditivo central pelo nervo auditivo. Dispositivos eletrônicos como o aparelho de amplificação sonora individual, o implante coclear e o sistema de frequência modulada são opções para a habilitação auditiva destes pacientes para diminuir a privação sensorial e estimular a aquisição e desenvolvimento da linguagem. Este estudo propõe investigar os resultados de linguagem oral de crianças com DENA que fazem uso de diferentes dispositivos eletrônicos em interface com os resultados de percepção auditiva da fala e comparar com os resultados obtidos de crianças sem queixas auditivas ou de linguagem. Participaram do estudo 19 crianças com idade entre seis e 12 anos incompletos com diagnóstico de DENA, divididas em usuárias de implante coclear e usuárias de aparelhos de amplificação sonora individuais, e pareadas com 28 crianças do grupo controle de acordo com a idade na avaliação e o sexo. A análise dos resultados mostrou que crianças com DENA não apresentam desempenho de linguagem esperado para a idade cronológica, sem diferença de resultados entre os dispositivos eletrônicos utilizados. O vocabulário receptivo e a porcentagem de consoantes corretas apresentaram correlação com todos os outros aspectos avaliados. A sintaxe e o vocabulário receptivo estão correlacionados com a percepção auditiva de fala na avaliação com sentenças, mas não com palavras. O único aspecto sociodemográfico que apresentou correlação significativa com as demais variáveis foi o nível socioeconômico. Com o presente estudo é possível concluir que as crianças com DENA necessitam de avaliação e intervenção voltadas para habilidades específicas e complexas da linguagem oral e da percepção auditiva da fala para um prognóstico mais otimista com relação ao desenvolvimento da linguagem oral próxima da normalidade para a idade cronológica. 
Palavras-chave: Perda Auditiva Neurossensorial. Linguagem. Percepção da Fala. Implantes Cocleares. Auxiliares de Audição. 